\title{
A Comparison of MMPI-2 Profiles Between Parental Alienation Cases and Custody Cases
}

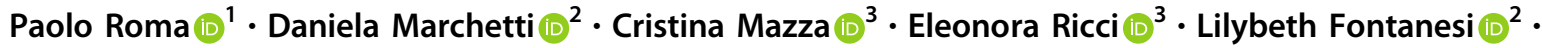 \\ Maria Cristina Verrocchio $\mathbb{1}^{2}$
}

Accepted: 9 August 2021 / Published online: 26 August 2021

(c) The Author(s) 2021

\begin{abstract}
The present study aimed at understanding the personality features of mothers and fathers engaged in parental alienation-a family dynamic in which one parent behaves in a way that foments a child's unfounded emotional rejection of the other parent. The process is considered a complex form of child psychological maltreatment, with significant negative consequences. In cases of conflictual separation and divorce, parental alienation can be difficult—yet important—to identify. In this context, use of psychological assessment to understand parents' personality characteristics may facilitate the early identification of parental alienation and related abuses. A comparative analysis of the Minnesota Multiphasic Personality Inventory-2 profiles of 41 couples engaged in parental alienation and 39 control couples (i.e., not involved in parental alienation) was used to assess the personality characteristics of mothers and fathers engaged in parental alienation. The results indicated that mothers who were classified as alienating presented a faking-good defensive profile, denied hostile and negative impulses, blamed others for their problems, and displayed excessive sensitivity. On the other side, fathers who were classified as targets of alienating behaviors were adapted to chronic depressive states, social isolation, and interpersonal conflict. The results suggest that the personality profile of parents involved in parental alienation may provide useful insight for custodial cases, prevent further abuse, and contribute to improving psychological and rehabilitative programs. Clinical and forensic implications are discussed.
\end{abstract}

Keywords Parental alienation $\cdot$ Alienating behaviors $\cdot$ Child custody disputes $\cdot$ Divorced parents $\cdot$ MMPI-2

\section{Highlights}

- Parental alienation is a complex form of family violence/maltreatment, with significant negative consequences.

- Mothers classified as alienating showed a faking-good defensive profile, denied negative impulses, and blamed others for their problems.

- Fathers classified as targeted showed depressive states, social isolation, and interpersonal conflict.

Lilybeth Fontanesi

lilybeth.fontanesi@unich.it

1 Department of Human Neuroscience, Sapienza University of Rome, Roma, Italy

2 Department of Psychological, Health and Territorial Sciences, G. d'Annunzio University of Chieti-Pescara, Chieti, CH, Italy

3 Department of Neuroscience, Imaging and Clinical Sciences G. d'Annunzio University of Chieti-Pescara, Chieti, CH, Italy

\section{Introduction}

Parental alienation is a complex family dynamic in which one parent (the preferred or alienating parent) engages in long-term aggressive, coercive, and manipulative behaviors (alienating behaviors) to negatively influence their child's relationship with the other parent (the targeted parent), with the intention of fomenting the child's unfounded emotional rejection of the other parent (Baker, 2007; Harman et al., 2018). As such, parental alienation represents a multifaceted, hostile, and instrumental form of psychological abuse, resulting in the child's rejection of the targeted parent for illogical, false, and exaggerated reasons (Harman 
et al., 2018). The dynamic was first recognized in the late 1980s and, since that time, it has been widely explored within the psychological and forensic literature (Baker, 2005, 2007; Harman et al., 2019; Lorandos, 2020; Siracusano et al., 2015; Verrocchio et al., 2018). Nonetheless, parental alienation remains a controversial topic and further empirical research is required to facilitate its early identification (Campbell, 2020; Harman et al., 2020; Johnston \& Sullivan, 2020; Warshak, 2020).

This specific family dynamic mostly occurs during or after parental separation or divorce (e.g., during child custody disputes), with the result that the child allies strongly with the preferred parent and rejects a relationship with the targeted parent, without legitimate reasons for doing so (Lorandos et al., 2013). In this situation, the targeted parent often feels defeated and no longer worthy of the child's love and attention; this victimization can even extend to his/her wider family (Harman et al., 2019). Importantly, parental alienation occurs in the absence of maltreatment by the targeted parent and after a positive and caring relationship has been established between the targeted parent and the child; the alienating behaviors of the preferred parent then manifest the child's rejection of the targeted parent (Baker, 2020). The alienating process includes abusive and manipulative strategies, such as conditioning, denying, and influencing communication, as well as forcing the child to reject the other parent by choosing between the two. The literature identifies specific alienating behaviors, such as: criticizing the targeted parent in front of the child, limiting and obstructing the child's communication with the targeted parent, telling the child the targeted parent is dangerous and does not love him/her, entrusting the child with legal or private information about the parents' relationship, asking the child to keep secrets from and spy on the targeted parent, referring to the targeted parent using his/her personal name (rather than "daddy"/"mommy"), and undermining the targeted parent's authority by cultivating and promoting child independency (Baker \& Darnall, 2006). These behaviors, repeated over time, aim at distancing the child from the targeted parent, increasing the targeted parent's anger and hurt, and provoking conflict between the child and the targeted parent. Alienation from one's child may be traumatic, and indeed targeted parents often experience frustration, stress, helplessness, loss, and suicidal ideation (LeeMaturana et al., 2019; Poustie et al., 2018). However, the consequences of parental alienation not only impact the targeted parent and his/her relationship with the child, but they also have significant repercussions for the child's mental health and wellbeing.

Recent studies have identified parental alienation as a form of family violence that can result in traumatized children being located with an abusive parent who is likely to eventually re-traumatize them (Harman et al.,
2018; Johnston \& Sullivan, 2020). In this perspective, it is fundamental to discriminate between family violence and alienation. Research has revealed that it is unnatural for a child to refuse a parent; thus, when a child resolutely spurns a parent outside of a context of confirmed violence, neglect, or poor parenting, it may be assumed that the other parent is practicing alienating behaviors (Harman et al., 2018; Kruk, 2018). Of note, the literature attests that alienating behaviors, in the absence of other forms of parental abuse (e.g., sexual or physical abuse), are more common among maternal research samples than paternal research samples (Austin et al., 2013; Poustie et al., 2018). Although there are several potential explanations for this, cultural context may be particularly relevant. For example, in some cultures (e.g., the Italian culture), mothers involved in child custody disputes are assumed to be the primary parent and the gatekeeper of their child's relationships with others, including the father. Therefore, mothers are more frequently awarded child custody, with the result that their children spend more time with them, with the potential for nurturing a deeper, closer, and more dependent relationship. Within this relational context, alienating behaviors may occur. This may go some way to explaining why alienating behaviors have been observed more frequently in female samples, even though parental roles (alongside legal and social frameworks) have undergone significant structural change, resulting in a more equal power dynamic between parents, encouraging split custody agreements. In fact, research has shown that the more time that both conflictual parents spend with their children, the more likely it is that both will engage in alienating behaviors (Johnston \& Sullivan, 2020).

The literature on parental alienation suggests that it is a serious form of child emotional abuse associated with physical abuse and neglect. Children who adopt the hatred of the alienating parent tend to hate themselves, feel less happy, and feel helpless and unwanted by the targeted parent (Kruk, 2018). In particular, the negative outcomes of alienating behaviors on children range from depression to anxiety, externalizing behaviors, substance use/abuse, low self-esteem, and poor academic performance (Baker \& BenAmi, 2011; Verrocchio et al., 2019; von Boch-Galhau, 2018).

The severity of these outcomes on targeted parents and children-particularly within the context of conflictual separation and divorce - call for the early identification of parents carrying out alienating behaviors. Researchers have proposed several variables as contributing factors to parental alienation, including: the personality characteristics of family members, the nature of the parental relationship, the nature of the parent-child relationship, parents' links with their family of origin, and environmental and social factors (Birgden \& Cucolo, 2011; Fidler et al., 2012; Gennari \& 
Tamanza, 2017; Harman et al., 2016; Saini et al., 2016; Verrocchio et al., 2018). Studies have also shown that parents who are classified as alienating tend to implement primitive defense mechanisms, such as projection, denial, splitting, idealization, and devaluation (Bernet et al., 2018; Gordon et al., 2008); they also demonstrate maladaptive personality traits (e.g., histrionic, paranoid, borderline, and narcissistic traits) and higher levels of psychopathology (e.g., substance abuse, psychosis, and suicidal ideation), and they tend to respond to the parental separation with anger and hatred, rather than sadness or loss (Demby, 2009; Fidler \& Bala, 2010; Johnston et al., 2005; Verrocchio et al., 2018). Preferred parents have also been found to be typically jealous, angry, emotionally vulnerable, and dependent on others (in some cases, even their children) for the consolidation of their self-esteem (Harman et al., 2016). Finally, they have been shown to act impulsively, with poor management of personal boundaries and relations, and to dichotomize the world around them and refuse to accept responsibility for their involvement in relational and family problems, showing a lack of remorse or guilt for their behaviors (Harman et al., 2018).

Some studies have investigated the personality traits of child custody litigants using Minnesota Multiphasic Personality Inventory-2 (MMPI-2) scales, which are frequently applied in forensic contexts to provide a reliable measurement of personality characteristics (Burla et al., 2019; Mazza et al., 2019; Mazza et al., 2020; Roma et al., 2020a, b). Roma et al. (2014) considered 509 Italian parents (247 couples) undergoing a court-ordered MMPI-2 assessment in the context of a child custody dispute between 2006-2010. The authors found that the child custody litigant mothers appeared deeply motivated to display a faking-good defensive profile. Compared to the child custody litigant men, they also demonstrated lower levels of cynicism and antisocial behaviors, describing themselves as socially desirable, conventional, conformist, loyal, and fair ( $\mathrm{L}$ scale). Furthermore, they had a greater tendency to deny faults and complaints ( $\mathrm{K}$ scale), and they were more likely to exaggerate their benevolence and morality ( $\mathrm{S}$ scale). These results were recently confirmed by research on mothers' MMPI-2 personality traits in 58 parental alienation cases (Roma et al., 2020a).

Most studies on the personality characteristics of parents carrying out alienating behaviors have found significant differences between men and women (Carr et al., 2005; Fariña et al., 2017; Harman et al., 2020; Mazza et al., 2019). Verrocchio et al. (2018) assessed 160 families in child custody disputes to gather knowledge about the psychological features of parents engaged in parental alienation and to detect other significant factors linked to this specific family dynamic. The authors found that a significant percentage of parents classified as alienating presented a dysfunctional personality profile with the potential to develop into a personality disorder involving significant psychological suffering. In more detail, fathers were the most frequently rejected by children. Mothers tended to be more anxious and depressed-as found in previous studies (Baker, 2010; Johnston et al., 2005; Warshak, 2010)-and characterized by histrionic, dependent, and passive-aggressive personality traits. Fathers (who have been less studied in the literature) tended to present mostly paranoid, narcissistic, and impulsive personality traits (Verrocchio et al., 2018). The importance of personality assessment in parental alienation cases is twofold. On the one hand, while it is true that personality disorders do not necessarily represent a risk factor for parental alienation, the identification of psychological vulnerabilities within the context of conflictual separation or divorce is fundamental for preventing the onset of this family dynamic, which would negatively impact the child. On the other hand, it is essential to improve our understanding of the personality traits and personality disorders of parents involved in parental alienation dynamics undergoing conflictual separation or divorce, in order to develop effective interventions (e.g., for individual and family therapy, parental alienation-specific treatment, and child therapy) to improve family functioning, reduce alienating behaviors, enhance personal coping strategies, and treat psychological symptoms (Mercer, 2019b, a; Poustie et al., 2018; Templer et al., 2017).

Starting from the results of Roma et al. (2020a) study, which analyzed 58 mothers classified as alienating according to the MMPI-2 dimensions of self-representation and narcissism, the present study aimed at improving our knowledge of the self-reported psychological and personality characteristics of parents involved in parental alienation dynamics. To the best of our knowledge, no other study has analyzed the MMPI-2 personality characteristics of preferred and targeted child custody litigant parents. Specifically, the study aimed at examining potential differences in MMPI-2 profiles between (a) divorced mothers carrying out alienating behaviors and divorced mothers with no involvement in parental alienation; and (b) targeted divorced fathers and non-targeted divorced fathers.

\section{Methods}

\section{Participants}

Ninety-five case files were collected from five custody evaluators. The evaluators were not members of the research team, but psychologists who had been identified from the professional registers of five of the major Italian courts (i.e., Milan, Turin, Rome, Naples, Palermo; https://www.istat.it/it/files//2016/11/matrimoni-separazionidivorzi-2015.pdf). Each had more than 10 years' experience evaluating child custody agreements. The evaluators provided written informed consent to participate, and the 
research team agreed to inform them of the results of the study, in order to improve their knowledge and expertise. Each evaluator provided 10 consecutive parental alienation (PA) case files and 10 consecutive control (No-PA) case files of mothers and fathers who had been evaluated in the context of a child custody case during the period January 2017-May 2019. Two of the five evaluators had fewer than 10 PA case files (i.e., 7 and 8, respectively). The final set of 95 anonymous case files was examined by the research team according to the following criteria. The inclusion criteria for PA cases were: (a) parents aged 18 years or older; and (b) mothers who explicitly or implicitly supported the child's refusal of their father, had at least one child who refused their father (for a duration of at least 1 year), had a minimum reading level of a 6th grade equivalent, and had a valid MMPI-2 profile. The exclusion criteria were: (a) mothers and fathers who had not been born and raised in Italy; (b) cases with allegations of violence (also ongoing) that could potentially explain the child's refusal of the targeted parent; (c) cases relating to child protection, as differences have been found between child protection and child custody disputes (Resendes \& Lecci, 2012); and (d) cases in which informed consent was not provided for future research purposes. Accordingly, six cases were excluded. The complete PA case files (proceedings and expert opinions) were evaluated by two of the authors, who confirmed that the inclusion criteria were met in all cases. Inclusion criteria for the control group were as follows: parents aged 18 years or older, with no prior display or accusation of PA, a minimum reading level of a 6th grade equivalent, and a valid MMPI-2 profile. The test exclusion criteria (see "Materials and Methods" section) led to the elimination of nine protocols, due to a Cannot Say Scale > 30 or a VRIN or TRIN T-score $>80$.

In total, 80 case files of parents involved in custody disputes were included in the study. Of these, 39 consisted of divorced mothers classified as alienating $(\mathrm{PA} / \mathrm{m})$ and fathers classified as targeted (PA/f), while 41 consisted of divorced mothers classified as non-alienating (No-PA/m) and fathers classified as non-targeted (No-PA/f). Table 1 presents the descriptive statistics for each of the four groups.

In accordance with the Declaration of Helsinki, the study was conducted following the written informed consent of all subjects, who were asked to participate in research on "assessment tools in forensic evaluation." The study was approved by the local ethics committee (Board of the Department of Human Neuroscience, Sapienza University of Rome).

\section{Materials}

The Minnesota Multiphasic Personality Inventory-2 (MMPI-2; Butcher, 2001) was employed as the single measure. The
Table 1 Descriptive statistics of mothers (PA/m and No-PA/m) and fathers (PA/f and No-PA/f).

\begin{tabular}{cllll}
\hline & $\begin{array}{l}\mathrm{PA} / \mathrm{m} \\
N=39\end{array}$ & $\begin{array}{l}\text { No-PA/m } \\
N=41\end{array}$ & $\begin{array}{l}\mathrm{PA} / \mathrm{f} \\
N=39\end{array}$ & $\begin{array}{l}\text { No-PA/f } \\
N=41\end{array}$ \\
\hline $\begin{array}{c}\text { Age years } \\
M(S D)\end{array}$ & $40.05(5.8)$ & $40.85(5.7)$ & $44.85(9.4)$ & $42.39(9.0)$ \\
$\quad \begin{array}{l}\text { Min-Max } \\
\text { Education }\end{array}$ & $25-50$ & $31-54$ & $25-60$ & $25-59$ \\
$\quad M(S D)$ & $14.29(2.7)$ & $14.54(3.9)$ & $11.77(4)$ & $12.93(3.9)$ \\
$\quad$ Min-Max & $8-19$ & $8-22$ & Aug-23 & $8-23$ \\
\hline
\end{tabular}

$\mathrm{PA} / \mathrm{m}$ : mothers classified as alienating; No-PA/m: mothers classified as non-alienating; PA/f: fathers classified as targeted; No-PA/f: fathers classified as non-targeted. No statistically significant differences were observed between mothers (PA/m vs. No-PA/m) and between fathers (PA/f vs. No-PA/f), on age and education.

MMPI-2 is the most widely used personality measure in clinical and forensic settings (Archer et al., 2006; Otto, 2002; Siegel \& Langford, 1998; Siegel, 1996). In the present study, the full version of the MMPI-2 was administered individually to all participants, according to standard instructions. The Italian version of the inventory consists of 567 items (Pancheri \& Sirigatti, 1995). According to the technical manual (Butcher, 2001), protocols with a Cannot Say Scale $>30$ or a VRIN or TRIN T-score $>80$ were excluded. Exclusions were not made on the basis of other validity scales, ensuring a full range of validity scale scores for the analysis (nevertheless, in accordance with the technical manual, no exclusions would have been made). According to the clinical meaning of the scales, previous studies using the MMPI and MMPI-2, and other research on child custody litigant personality characteristics (Roma et al., 2014), the following MMPI-2 scales were selected for the analysis: (a) 3 principal validity scales (F, L, K), (b) 10 standard clinical scales, and (c) 31 Harris and Lingoes subscales. MMPI-2 scale scores were calculated according to the traditional method, using standard $T$ scores $(M=50, S D=10)$ (Tellegen \& Ben-Porath, 1992). The MMPI-2 $T$ score classification is: $55-60=$ moderately high; $60-65=$ high; and 65-70 = very high (Butcher, 2001).

\section{Statistical Analysis}

Multivariate analyses of variance (MANOVAs) were run using the two maternal behaviors (alienation vs. non-alienation) and paternal attitudes (targeted vs. non-targeted) as independent variables. $T$ scores of the selected MMPI- 2 scales were used as dependent measures. Bonferroni correction was applied for multiple comparisons and the effect sizes of score differences between groups were examined. A non-parametric chi-square test was used to compare the elevation percentages on the validity and clinical scale $T$ scores $(>65)$ between PA/m and No-PA/m, and between PA/f and No-PA/f, respectively. For each test, the effect size was also inspected. Finally, to 
Table 2 Differences in MMPI-2 validity and clinical scale $T$ scores between PA/m and No$\mathrm{PA} / \mathrm{m}$.

\begin{tabular}{|c|c|c|c|c|c|c|}
\hline & MMPI-2 & $\begin{array}{l}\mathrm{PA} / \mathrm{m} \\
N=39 \\
M(S D)\end{array}$ & $\begin{array}{l}\text { No-PA/m } \\
N=41 \\
M(S D)\end{array}$ & $F$ & $p$ & $\operatorname{par\eta }^{2}$ \\
\hline \multirow{3}{*}{$\begin{array}{l}\text { Validity } \\
\text { scales }\end{array}$} & $\mathrm{L}$ & $65.10(9.1)$ & $59(7.7)$ & 10.50 & 0.002 & 0.119 \\
\hline & $\mathrm{F}$ & $45.56(6.4)$ & $45.95(5.9)$ & 0.08 & 0.779 & 0.001 \\
\hline & $\mathrm{K}$ & $65.41(7.9)$ & $59.12(6.1)$ & 15.98 & $<0.001$ & 0.170 \\
\hline \multirow{8}{*}{$\begin{array}{l}\text { Clinical } \\
\text { scales }\end{array}$} & $1-\mathrm{Hs}$ & $49.72(9.5)$ & 48.44 (9.9) & 0.34 & 0.558 & 0.004 \\
\hline & 2-D & $48.15(7.9)$ & $50.12(7.1)$ & 1.37 & 0.245 & 0.017 \\
\hline & $\begin{array}{l}\text { 3-Hy } \\
4-\mathrm{Pd}\end{array}$ & $\begin{array}{l}53.49(7.1) \\
54.46(4.7)\end{array}$ & $\begin{array}{l}52.34(7.5) \\
52.46(5.9)\end{array}$ & $\begin{array}{l}0.49 \\
2.74\end{array}$ & $\begin{array}{l}0.484 \\
0.102\end{array}$ & $\begin{array}{l}0.006 \\
0.034\end{array}$ \\
\hline & $\begin{array}{l}\text { 5-Mf } \\
6-\mathrm{Pa}\end{array}$ & $\begin{array}{l}52.74(8.2) \\
62.64(10.2)\end{array}$ & $\begin{array}{l}52.85(6.9) \\
51.95(9.3)\end{array}$ & $\begin{array}{r}0.00 \\
24.18\end{array}$ & $\begin{array}{r}0.949 \\
<0.001\end{array}$ & $\begin{array}{l}0.000 \\
0.237\end{array}$ \\
\hline & 7-Pt & $47.54(8.9)$ & $51.88(6.9)$ & 5.97 & 0.017 & 0.071 \\
\hline & $8-\mathrm{Sc}$ & $52.08(8.9)$ & $48.59(10.1)$ & 2.65 & 0.107 & 0.033 \\
\hline & 9-Ma & $46.10(5.7)$ & $47.32(9.8)$ & 0.45 & 0.502 & 0.006 \\
\hline & $0-\mathrm{Si}$ & $44.87(9.0)$ & $50(14.2)$ & 3.68 & 0.058 & 0.045 \\
\hline
\end{tabular}

$\mathrm{PA} / \mathrm{m}$ : mothers classified as alienating; No-PA/m: mothers classified as non-alienating. investigate any self-reported personality characteristics that might identify mothers as more likely to engage in alienating behaviors and fathers as more likely to become targeted, a logistic regression was run using variables found to differ between the two groups of mothers (PA/m and No-PA/m) and the two groups of fathers (PA/f and No-PA/f) in the previous MANOVAs, as predictors. All analyses were performed using SPSS for Windows, version 25.0 (IBM Inc., Armonk, New York, USA).

\section{Results}

\section{Comparisons Between Mothers Classified as Alienating (PA/m) and Mothers Classified as Non- Alienating (No-PA/m)}

A $2 \times 13$ MANOVA (groups $x$ validity and clinical MMPI2 scales) showed a significant effect of alienation status on the MMPI-2 validity and clinical scales, $V=0.480, F(13$, $66)=4.684, p<0.001, \operatorname{par}^{2}=0.480$. Separate univariate ANOVAs on the outcome variables revealed a significant effect of the grouping variable on: (a) the $\mathrm{L}$ and $\mathrm{K}$ validity scales and (b) the 6-Pa and 7-Pt clinical scales (see Table 2).

The $\mathrm{PA} / \mathrm{m}$ group scored higher on the $\mathrm{L}$ and $\mathrm{K}$ validity scales, as well as the 6-Pa clinical scale than the No-PA/m group. Mothers classified as alienating tended to show more underreporting profiles, characterized by virtuous and socially desirable behaviors, together with a high level of interpersonal suspiciousness. In contrast, mothers in the control group scored higher on the 7-Pt scale, demonstrating greater anxiety, fear, and worry.

A $2 \times 3$ MANOVA (groups $x$ three Harris-Lingoes MMPI-2 Paranoia subscales) showed a significant effect of alienation status on the MMPI- 2 scales, $V=.513 F$ (3, $76)=26.724, p<0.001, \operatorname{par\eta }^{2}=0.513$. In more detail, separate univariate ANOVAs on the outcome variables revealed a significant effect of parental alienation on $\mathrm{Pa} 3[F$ $(1,78)=76.352, p=p<0.001$, parn $\left.^{2}=0.495\right]$. No significant effects were found for Pa1 $[F(1,78)=0.046, p=$ 0.813, parn $\left.^{2}=0.001\right]$ or $\mathrm{Pa} 2[F(1,78)=0.039, p=0.845$, $\left.\operatorname{par\eta }^{2}=0.000\right]$ (see Table 3$)$.

Compared to controls, mothers who were classified as alienating scored significantly higher on Pa3, describing themselves as naïve about others and seeing their self and others as trustworthy and honest with high moral standards, often denying hostility.

Table 4 shows the non-parametric chi-square tests used to compare elevation percentages on the validity and clinical scale $T$ scores $(>65)$ between these two groups of mothers.

Twenty-one (out of 39) participants in the PA/m group demonstrated clinical elevation $(T>65)$ on the $\mathrm{L}$ and $\mathrm{K}$ scales and 20 showed clinically elevated $T$ scores on the 6-Pa scale. Four (out of 41) mothers in the control group demonstrated clinical elevation on the 9-Ma scale.

A multiple logistic regression analysis was performed using the enter method. Alienating status was set as the dependent variable while the MMPI-2 scales were used as predictors. The inserted variables were those showing a statistical difference in the previous MANOVA comparing the two groups of mothers (i.e., L, K, Pa3, 7-Pt). The 6-Pa clinical scale was not included because its subscale $(\mathrm{Pa} 3)$ was instead considered; this subscale was found to differ between the PA/m and No-PA/m groups. The Wald test was used to evaluate the contribution of each predictor to the model. A predictor was entered into the regression equation when the probability $(p)$ was 0.05 . Overall prediction success was $90 \%$ (92.3\% for $\mathrm{PA} / \mathrm{m} ; 87.8 \%$ for $\mathrm{No}-\mathrm{PA} / \mathrm{m})$. The 
Table 3 Differences in MMPI-2 6-Pa Harris-Lingoes subscales between $\mathrm{PA} / \mathrm{m}$ and No-PA/m.

\begin{tabular}{|c|c|c|c|c|c|c|}
\hline & MMPI-2 & $\begin{array}{l}\mathrm{PA} / \mathrm{m} \\
N=39 \\
M(S D)\end{array}$ & $\begin{array}{l}\text { No-PA/m } \\
N=41 \\
M(S D)\end{array}$ & $F$ & $p$ & parn ${ }^{2}$ \\
\hline \multirow[t]{3}{*}{ Harris- Lingoes $\mathrm{Pa}$ subscale } & PA1 & $54.51(9.8)$ & $54.05(9.5)$ & 0.04 & 0.831 & 0.001 \\
\hline & PA2 & $46.69(8.5)$ & $46.27(10.6)$ & 0.04 & 0.845 & 0.000 \\
\hline & PA3 & $65.44(7.7)$ & $51.76(6.3)$ & 76.35 & $<0.001$ & 0.495 \\
\hline
\end{tabular}

$\mathrm{PA} / \mathrm{m}$ : mothers classified as alienating; No-PA/m: mothers classified as non-alienating.

\begin{tabular}{|c|c|c|c|c|c|c|c|}
\hline & MMPI-2 & $\mathrm{T}>65$ & $\begin{array}{l}\mathrm{PA} / \mathrm{m} \\
(N=39)\end{array}$ & $\begin{array}{l}\text { No-PA/m } \\
(N=41)\end{array}$ & $X^{2}$ & $p$ & V \\
\hline \multirow{3}{*}{$\begin{array}{l}\text { Validity } \\
\text { scales }\end{array}$} & $\mathrm{L}$ & & $21(70 \%)$ & $9(30 \%)$ & 8.68 & 0.003 & 0.329 \\
\hline & $\mathrm{F}$ & & $1(50 \%)$ & $1(50 \%)$ & 0.001 & 0.971 & 0.004 \\
\hline & K & & $21(72.4 \%)$ & $8(27.6 \%)$ & 10.20 & 0.001 & 0.357 \\
\hline \multirow{9}{*}{$\begin{array}{l}\text { Clinical } \\
\text { scales }\end{array}$} & $1-\mathrm{Hs}$ & & $3(50 \%)$ & $3(50 \%)$ & 004 & 0.949 & 0.007 \\
\hline & $2-\mathrm{D}$ & & $3(60 \%)$ & $2(40 \%)$ & 0.27 & 0.603 & 0.058 \\
\hline & 3-Hy & & $3(60 \%)$ & $2(40 \%)$ & 0.27 & 0.603 & 0.058 \\
\hline & 4-Pd & & $1(33.3 \%)$ & $2(66.7 \%)$ & 0.30 & 0.586 & 0.061 \\
\hline & 6-Pa & & $20(83.3 \%)$ & $4(16.7 \%)$ & 16.41 & $<0.001$ & 0.453 \\
\hline & 7-Pt & & $3(75 \%)$ & $1(25 \%)$ & 1.16 & 0.281 & 0.120 \\
\hline & 8-Sc & & $5(71.4 \%)$ & $2(28.6 \%)$ & 1.58 & 0.209 & 0.140 \\
\hline & 9-Ma & & $0(0 \%)$ & $4(100 \%)$ & 4.01 & 0.045 & 0.224 \\
\hline & $0-\mathrm{Si}$ & & $1(14.3 \%)$ & $6(85.7 \%)$ & 3.65 & 0.056 & 0.214 \\
\hline
\end{tabular}

$\mathrm{PA} / \mathrm{m}$ : mothers classified as alienating; No-PA/m: mothers classified as non-alienating.
Table 4 Differences in $T$ score frequencies $>65$ on the MMPI-2 validity and clinical scales between $\mathrm{PA} / \mathrm{m}$ and No-PA/m.
Table 5 Logistic regression model predicting group membership of $\mathrm{PA} / \mathrm{m}$ vs. No-PA/m.

\begin{tabular}{lrrrrrr}
\hline & \multicolumn{1}{l}{ B } & S.E. & \multicolumn{1}{c}{ Wald } & df & \multicolumn{1}{l}{ Sign. } & Exp (B) \\
\hline $\mathrm{L}$ & 0.080 & 0.041 & 3.843 & 1 & 0.050 & 1.084 \\
$\mathrm{~K}$ & -0.048 & 0.066 & 0.522 & 1 & 0.470 & 0.954 \\
$\mathrm{~Pa} 3$ & 0.295 & 0.070 & 17.629 & 1 & $<0.001$ & 1.343 \\
$7-\mathrm{Pt}$ & -0.061 & 0.048 & 1.616 & 1 & 0.204 & 0.941 \\
\hline
\end{tabular}

$\mathrm{PA} / \mathrm{m}$ : mothers classified as alienating; No-PA/m: mothers classified as non-alienating.

alienation status on the MMPI-2 scales, $V=0.722 F(14$, $65)=12.066, p<0.001$, parn $^{2}=0.722$. In more detail, separate univariate ANOVAs on the outcome variables revealed a significant effect of parental alienation on: (a) the D1 and D5 Harris-Lingoes MMPI-2 Depression (2-D) subscales, and (b) all Harris-Lingoes MMPI-2 Social Introversion (0-Si) subscales (see Table 7).

Fathers classified as targeted scored higher on all significant subscales, showing a more problematic profile. They were more introverted, easily influenced by the opinions of others, and often in denial of their impatience.

Table 8 shows the non-parametric chi-square tests used to compare elevation percentages on the validity and clinical scale $T$ scores ( $>65$ ) between PA/f and No-PA/f. 
Table 6 Differences in the MMPI-2 validity and clinical scales between PA/f and No-PA/ f.

Table 7 Differences in the MMPI-2 2-D, 8-Sc, and 0-Si Harris-Lingoes Subscales Between PA/f and No-PA/f.

\begin{tabular}{|c|c|c|c|c|c|c|}
\hline & MMPI-2 & $\begin{array}{l}\mathrm{PA} / \mathrm{f} \\
N=39 \\
M(S D)\end{array}$ & $\begin{array}{l}\text { No-PA/f } \\
N=41 \\
M(S D)\end{array}$ & $F$ & $p$ & parn $^{2}$ \\
\hline \multirow{3}{*}{$\begin{array}{l}\text { Validity } \\
\text { scales }\end{array}$} & $\mathrm{L}$ & $47.03(8.8)$ & $49.95(9,7)$ & 1.99 & 0.163 & 0.025 \\
\hline & $\mathrm{F}$ & $55.10(9.7)$ & $54.59(10,3)$ & 0.05 & 0.817 & 0.001 \\
\hline & $\mathrm{K}$ & $39.77(7.9)$ & $43.22(9,9)$ & 2.95 & 0.090 & 0.036 \\
\hline \multirow{10}{*}{$\begin{array}{l}\text { Clinical } \\
\text { scales }\end{array}$} & $1-\mathrm{Hs}$ & $56.38(13.3)$ & $57.66(12,8)$ & 0.19 & 0.664 & 0.002 \\
\hline & $2-\mathrm{D}$ & $62.08(10.6)$ & $54.15(10,9)$ & 10.79 & 0.002 & 0.122 \\
\hline & 3-Hy & $53.95(12.5)$ & $53.90(11.5)$ & 0.00 & 0.986 & 0.000 \\
\hline & 4-Pd & $61.82(11.3)$ & $62.32(12,7)$ & 0.34 & 0.855 & 0.000 \\
\hline & 5-Mf & $53.92(7)$ & $52.44(6)$ & 1.03 & 0.313 & 0.013 \\
\hline & 6-Pa & $61.62(11.5)$ & $61.56(13,3)$ & 0.00 & 0.985 & 0.000 \\
\hline & 7-Pt & $56(12.9)$ & $53.56(14,4)$ & 0.64 & 0.427 & 0.008 \\
\hline & $8-\mathrm{Sc}$ & $59.18(8.4)$ & $52.73(12,6)$ & 7.15 & 0.009 & 0.084 \\
\hline & 9-Ma & $51.51(10.5)$ & $52(10,1)$ & 0.05 & 0.838 & 0.001 \\
\hline & $0-\mathrm{Si}$ & $62.36(11.4)$ & $54.66(12], 9)$ & 7.90 & 0.006 & 0.092 \\
\hline
\end{tabular}

PA/f: fathers classified as targeted; No-PA/f: fathers classified as non-targeted.

\begin{tabular}{|c|c|c|c|c|c|c|}
\hline & MMPI-2 & $\begin{array}{l}\mathrm{PA} / \mathrm{f} \\
N=39 \\
M(S D)\end{array}$ & $\begin{array}{l}\text { No-PA/f } \\
N=41 \\
M(S D)\end{array}$ & $F$ & $p$ & $\operatorname{par\eta }^{2}$ \\
\hline \multirow[t]{14}{*}{ Harris Lingoes Scales } & D1 & $58(8.1)$ & $46.05(6.1)$ & 55.89 & $<0.001$ & 0.417 \\
\hline & D2 & $49.74(9.6)$ & $51.17(8.9)$ & 0.47 & 0.492 & 0.006 \\
\hline & D3 & $48.54(10.1)$ & $48.51(8.9)$ & 0.00 & 0.990 & 0.000 \\
\hline & D4 & $46.74(7.5)$ & $44.85(5.2)$ & 1.72 & 0.193 & 0.022 \\
\hline & D5 & $51.72(7.9)$ & $45.46(7.5)$ & 13.04 & 0.001 & 0.143 \\
\hline & $\mathrm{SC} 1$ & $48.46(11.6)$ & $46.68(7.9)$ & 0.65 & 0.424 & 0.008 \\
\hline & $\mathrm{SC} 2$ & $47.15(9.4)$ & $46.32(9.4)$ & 0.18 & 0.671 & 0.002 \\
\hline & $\mathrm{SC} 3$ & $48.23(8.7)$ & $45.78(4.9)$ & 2.50 & 0.117 & 0.031 \\
\hline & $\mathrm{SC} 4$ & $45.33(8.1)$ & $44.63(5.8)$ & 0.20 & 0.657 & 0.003 \\
\hline & SC5 & $47.67(10.9)$ & $44.63(5.8)$ & 2.50 & 0.118 & 0.031 \\
\hline & SC6 & $49.72(11.7)$ & $47.95(8.2)$ & 0.62 & 0.435 & 0.008 \\
\hline & SI1 & $58.21(9.3)$ & $47.76(10.1)$ & 22.97 & $<0.001$ & 0.228 \\
\hline & SI2 & $59.74(7.6)$ & $52.15(10.6)$ & 13.47 & $<0.001$ & 0.147 \\
\hline & SI3 & $56.92(9.1)$ & $46.78(8.9)$ & 25.23 & $<0.001$ & 0.244 \\
\hline
\end{tabular}

PA/f: fathers classified as targeted; No-PA/f: fathers classified as non-targeted.
Fourteen (out of 39) participants in the PA/f group demonstrated clinical elevation $(T$ score $>65)$ on the 2-D scale.

A multiple logistic regression analysis was performed using the enter method. Alienated status was set as the dependent variable while MMPI-2 scales were used as predictors. The inserted variables were those showing a statistical difference in the previous multivariate ANOVA comparing fathers classified as targeted and those classified as non-targeted (i.e., D1, D5, Si1, Si2, Si3). The Wald test was used to evaluate the contribution of each predictor to the model. A predictor was entered into the regression equation when the probability $(p)$ was 0.05 . Overall prediction success was $85 \%$ (87.8\% for PA/ $\mathrm{f} ; 82.1 \%$ for No-PA/f). The prediction model showed goodness-of-fit to the observed data $\left(\chi^{2}[5]=55.283, p<\right.$ 0.001). Nagelkerke's R of 0.665 indicated a moderately strong relationship between the predictors and the dependent variable. The final prediction model was comprised of the D1 and D5 subscales. The 0-Si Harris-Lingoes subscales were excluded (see Table 9).

\section{Discussion}

The main purpose of the present research was to improve our understanding of the psychological and personality characteristics of parents involved in parental alienation dynamics. The study assessed 80 couples: 39 composed of 
Table 8 Differences in $T$ score frequencies $>65$ on the MMPI-2 validity and clinical scales between PA/f and No-PA/f.

\begin{tabular}{|c|c|c|c|c|c|c|c|}
\hline & MMPI-2 & $\mathrm{T}>65$ & $\begin{array}{l}\text { PA/f } \\
(N=39)\end{array}$ & No-PA/f $(N=41)$ & $X^{2}$ & $p$ & $\mathrm{~V}$ \\
\hline \multirow{3}{*}{$\begin{array}{l}\text { Validity } \\
\text { scales }\end{array}$} & $\mathrm{L}$ & & $4(40 \%)$ & $6(60 \%)$ & 0.35 & 0.554 & 0.066 \\
\hline & $\mathrm{F}$ & & $5(38.5 \%)$ & $8(61.5 \%)$ & 0.66 & 0.417 & 0.091 \\
\hline & $\mathrm{K}$ & & $0(0 \%)$ & $0(0 \%)$ & l & l & l \\
\hline \multirow{9}{*}{$\begin{array}{l}\text { Clinical } \\
\text { scales }\end{array}$} & $1-\mathrm{Hs}$ & & $13(52 \%)$ & $12(48 \%)$ & 0.154 & 0.695 & 0.044 \\
\hline & $2-\mathrm{D}$ & & $14(70 \%)$ & $6(30 \%)$ & 4.82 & 0.028 & 0.245 \\
\hline & 3-Hy & & $11(64.7 \%)$ & $6(35.7 \%)$ & 2.2 & 0.138 & 0.166 \\
\hline & 4-Pd & & $15(42.9 \%)$ & $20(57.1 \%)$ & 0.87 & 0.352 & 0.104 \\
\hline & 6-Pa & & $16(50 \%)$ & $16(50 \%)$ & 0.03 & 0.855 & 0.020 \\
\hline & 7-Pt & & $8(47.1 \%)$ & $9(52.9 \%)$ & 0.03 & 0.875 & 0.018 \\
\hline & $8-\mathrm{Sc}$ & & $9(60 \%)$ & $6(40 \%)$ & 0.94 & 0.334 & 0.108 \\
\hline & 9-Мa & & $4(40 \%)$ & $6(60 \%)$ & 0.35 & 0.554 & 0.066 \\
\hline & $0-\mathrm{Si}$ & & $12(54.5 \%)$ & $10(45.5 \%)$ & 0.41 & 0.523 & 0.071 \\
\hline
\end{tabular}

PA/f: fathers classified as targeted; No-PA/f: fathers classified as non-targeted.
Table 9 Logistic regression model predicting group membership of PA/f vs. No-PA/f.

\begin{tabular}{lrlrlll}
\hline & \multicolumn{1}{c}{ B } & S.E. & Wald & df & Sign. & Exp (B) \\
\hline D1 & 0.396 & 0.104 & 14.360 & 1 & $<0.001$ & 1.485 \\
D5 & -0.251 & 0.096 & 6.760 & 1 & 0.009 & 0.778 \\
SI1 & 0.022 & 0.047 & 0.231 & 1 & 0.631 & 1.023 \\
SI2 & 0.008 & 0.044 & 0.036 & 1 & 0.850 & 1.008 \\
SI3 & 0.073 & 0.052 & 1.973 & 1 & 0.160 & 1.076 \\
\hline
\end{tabular}

PA/f: fathers classified as targeted; No-PA/f: fathers classified as nontargeted.

mothers and fathers engaged in parental alienation and 41 comprised of control parents undergoing a court-ordered psychological evaluation of their personality and parenting ability in the context of a child custody dispute, without alienation.

The results revealed that mothers who were classified as alienating endorsed particular MMPI-2 items in an attempt to present themselves in a favorable light, as overly virtuous. They appeared deeply motivated to display a fakinggood defensive profile, showing few overt signs of emotional disturbance. The underreporting of symptoms on the MMPI-2 amongst child custody litigants is a well-known problem (Bagby et al.,1999; Fariña et al., 2017). However, the most interesting result of the present study concerns the MMPI-2 psychological profile of mothers classified as alienating; this profile highlighted a tendency to be excessively sensitive and overly responsive to others' opinions, as well as suspicious and guarded; to rationalize and blame others for one's own problems; and to be moralistic and rigid in one's own opinions and attitudes, emphasizing rationality (6-Pa and 6-Pa3 scales). Moreover, similar MMPI-2 personality profiles portrayed a proclivity to present oneself as socially and psychologically adapted and trusting, while simultaneously attempting to deny hostile and negative impulses, declare high moral standards, and express extremely naïve and optimistic attitudes about others, who are perceived as honest and unselfish (L, K, 6-Pa3 scales). Our data suggests that these characteristics were the strongest predictors of alienating behaviors. These results are in line with the previous study by Roma et al. (2020a), which found that mothers classified as alienating showed psychological profiles characterized by a high selffavorable bias (i.e., a tendency to present an image of adequacy and self-control that is incompatible with real life), rigid moral values, greater sensitivity to criticism, susceptibility to others' behaviors, and a tendency to deny negative dispositions in others.

On the other hand, the MMPI-2 profiles of fathers classified as targeted suggest that they may have had a depressed mood and lack of energy to cope with problems, as well as a proclivity to avoid reality by engaging in fantasy and daydreams (2-D, D1, D5, 8-Sc scales). Compared to the control group (composed of divorced fathers classified as non-targeted), fathers classified as targeted disclosed (in the MMPI-2) that they preferred to be alone or with a small group of friends, as they tended to feel uneasy and shy in social settings (0-Si, SI1, SI2, SI3 scales). Furthermore, due to their persistent dysfunctional relationship with their child's mother, many had also adapted to an unusually high level of interpersonal and social conflict. Research has shown that targeted parents may experience depression, anger, withdrawal, passivity, and a sense of disbelief due to the loss of a relationship with their child (Lee-Maturana et al., 2020; Lee-Maturana et al., 2019). These parents may also experience significant emotional distress as a result of several factors, including their attempts to maintain a relationship with their child, feelings of grief due to the loss of this relationship, low expectations of repairing this relationship, shame and humiliation associated with the fear 
that their social context will presume that their child's rejection is justified, acknowledgement of personal responsibility in the alienation process, and a lengthy adversarial litigation process (Baker \& Fine, 2014; Darnall \& Steinberg, 2008; Fidler \& Bala, 2010; Goldberg \& Goldberg, 2013; Whitcombe, 2017).

Considering the personality profiles found in the present study, some important clinical reflections may be drawn. The alienating process has severe consequences for both parents involved in alienation dynamics, and these consequences are likely to affect their social and personal lives, in different ways and to different degrees. This calls for the development of therapeutic interventions to restore parents' awareness of the conflict and situation and to strengthen their resilience and personal competencies, with the aim of re-establishing positive parenting. As suggested by the literature, empirical analyses of personality characteristics and individual and family processes that may reinforce parental alienation and allow it to persist over time are fundamental to improving court decisions (Johnston, 2003; Saini et al., 2016). Additionally, such knowledge is important in a clinical setting to guide and differentiate psychological interventions. Moreover, in the context of conflictual separations and child custody disputes, the abovementioned profiles may account for the frequent difficulties in engaging the parental dyad in post-court decisions. While MMPI-2 scores should not be interpreted deterministically, oppositional and rigid maternal behavior and a resigned and hopeless paternal attitude may represent significant obstacles for psychotherapists and family mediators working to restore a positive family system and recover an alienated parent-child relationship. Attorneys, custody child evaluators, and mental health professionals involved in child custody disputes should seek to recognize alienating dynamics early, in order to recommend adequate interventions. In this vein, the determination of specific personality features associated with alienating behaviors may be useful for preventing further negative outcomes in children.

The present findings contribute to the growing body of empirical research on parental alienation providing evidence-based information. Child custody cases require coordinated and collaborative therapeutic-court interventions involving a variety of professional figures, including legal professionals, psychologists, and consultants capable of assessing, evaluating, and determining custody agreements. The present results highlight the different personality profiles of maternal and paternal figures involved in parental alienation dynamics and underscore the importance of assessing the personality characteristics of parents involved in child custody disputes in order to direct mental health interventions and achieve better decisions in court. In this way, the gold standard of the "best interests of the child" may be maintained.
Despite the relevance of the results, the present study has some limitations. First, we must acknowledge the small number of participants; however, it should be noted that the research was based on child custody litigants, and not the general population. As the research was an ecological study based on child custody litigant case files, it was difficult to achieve a robust representation of the target population, especially with respect to parents engaged in parental alienation (also considering reservations linked to the legal context). Furthermore, the research focused on mothers classified as alienating and fathers classified as targeted. This focus on mothers' alienating behaviors was determined by the results of a recent study with a "high-conflict" Italian sample (Verrocchio et al., 2018), which found that, in $78 \%$ of the cases, the father was the targeted parent. Moreover, despite the given considerations, future research should address the personality characteristics of fathers carrying out alienating behaviors, especially in comparison with mothers, and explore how these characteristics might contribute to maintaining and establishing a fixed pattern of alienating behaviors. Additionally, we cannot exclude the possible effect of selection bias in the present study, as participants were chosen from a set of child custody cases. However, all parental alienation cases were classified by independent and expert custody evaluators according to the most recent criteria in the literature (Baker, 2020). An interesting direction for future research would be to apply a multidimensional assessment to corroborate expert evaluations with behavioral, self-referred, or informant interview data. Furthermore, in addition to assessing personality, future studies should also seek to collect information from multiple family informants and match this data with personality profiles, in order to generate a broader interpretation of alienating situations and behaviors.

\section{Data Availability}

The datasets generated during and/or analyzed during the current study are available from the corresponding author on reasonable request.

Author Contributions Author contributions: P.R., M.C.V., D.M. contributed to the conception of the study. Material preparation was done by P.R. and M.C.V. Data analysis was performed by C.M. The first draft of the paper was written by C.M., D.M., E.R. and L.F. All the authors commented on previous versions of the paper. All the authors read, revised, and approved the final version of the paper.

Funding This research did not receive any specific grant from funding agencies in the public, commercial, or not-for-profit sectors. Open access funding provided by Università degli Studi G. D'Annunzio Chieti Pescara within the CRUI-CARE Agreement

\section{Compliance with Ethical Standards}

Conflict of Interest The authors declare no competing interests. 
Ethical Approval The research was approved by the ethics committee of the Department of Human Neuroscience, Faculty of Medicine and Dentistry, Sapienza University of Rome.

Publisher's note Springer Nature remains neutral with regard to jurisdictional claims in published maps and institutional affiliations.

Open Access This article is licensed under a Creative Commons Attribution 4.0 International License, which permits use, sharing, adaptation, distribution and reproduction in any medium or format, as long as you give appropriate credit to the original author(s) and the source, provide a link to the Creative Commons license, and indicate if changes were made. The images or other third party material in this article are included in the article's Creative Commons license, unless indicated otherwise in a credit line to the material. If material is not included in the article's Creative Commons license and your intended use is not permitted by statutory regulation or exceeds the permitted use, you will need to obtain permission directly from the copyright holder. To view a copy of this license, visit http://creativecommons. org/licenses/by/4.0/.

\section{References}

Archer, R. P., Buffington-Vollum, J. K., Stredny, R. V., \& Handel, R. W. (2006). A survey of psychological test use patterns among forensic psychologists. Journal of Personality Assessment, 87(1), 84-94. https://doi.org/10.1207/s15327752jpa8701_07.

Austin, W. G., Pruett, M. K., Kirkpatrick, H. D., Flens, J. R., \& Gould, J. W. (2013). Parental gatekeeping and child custody/child access evaluation: Part I: conceptual framework, research, and application. Family Court Review, 51(3), 485-501. https://doi.org/10. 1111/fcre.12045.

Bagby, R. M., Nicholson, R. A., Buis, T., Radovanovic, H., \& Fidler, B. J. (1999). Defensive responding on the MMPI-2 in family custody and access evaluations. Psychological Assessment, 11(1), 24-28. https://doi.org/10.1037/1040-3590.11.1.24.

Baker, A. J. L. (2005). The long-term effects of parental alienation on adult children: a qualitative research study. American Journal of Family Therapy, 33(4), 289-302. https://doi.org/10.1080/ 01926180590962129.

Baker, A. J. L. (2007). Adult children of parental alienation syndrome. Norton.

Baker, A. J. L. (2010). Figli divisi: storie di manipolazione emotiva dei genitori nei confronti dei figli [Adult children of parental alienation syndrome]. Giunti Psychometrics.

Baker, A. (2020). Reliability and validity of the four-factor model of parental alienation. Journal of Family Therapy, 42(1), 100-118. https://doi.org/10.1111/1467-6427.12253.

Baker, A. J. L., \& Ben-Ami, N. (2011). To turn a child against a parent is to turn a child against himself: the direct and indirect effects of exposure to parental alienation strategies on self-esteem and wellbeing. Journal of Divorce and Remarriage, 52(7), 472-489. https://doi.org/10.1080/10502556.2011.609424.

Baker, A. J. L., \& Darnall, D. (2006). Behaviors and strategies employed in parental alienation. Journal of Divorce \& Remarriage, 45(1-2), 97-124. https://doi.org/10.1300/j087v45n01_06.

Baker, A. J. L., \& Fine, P. (2014). Surviving parental alienation. A journey of hope and dealing. Rowman \& Littlefield.

Bernet, W., Gregory, N., Reay, K. M., \& Rohner, R. P. (2018). An objective measure of splitting in parental alienation: the parental acceptance-rejection questionnaire. Journal of Forensic Sciences, 63(3), 776-783. https://doi.org/10.1111/1556-4029.13625.
Birgden, A., \& Cucolo, H. (2011). The treatment of sex offenders: evidence, ethics, and human rights. Sexual Abuse: Journal of Research and Treatment, 23(3), 295-313. https://doi.org/10. 1177/1079063210381412.

Burla, F., Mazza, C., Cosmo, C., Barchielli, B., Marchetti, D., Verrocchio, M. C., \& Roma, P. (2019). Use of the parents preference test in child custody evaluations: preliminary development of Conforming Parenting Index. Mediterranean Journal of Clinical Psychology, 7 (3), 1-17. https://doi.org/10.6092/2282-1619/2019.7.2213.

Butcher, J. N. (2001). Minnesota multiphasic personality inventory-2: manual for administration, scoring, and interpretation. University of Minnesota Press.

Campbell, J. (2020). Children resisting contact with a parent due to abuse, alienation, or other causes: can a proactive role for lawyers contribute to better outcomes? Family Court Review, 58(2), 456-469. https://doi.org/10.1111/fcre.12482.

Carr, G. D., Moretti, M. M., \& Cue, B. J. H. (2005). Evaluating parenting capacity: validity problems with the MMPI-2, PAI, CAPI, and ratings of child adjustment. Professional Psychology: Research and Practice, 36(2), 188-196. https://doi.org/10.1037/ 0735-7028.36.2.188.

Darnall, D., \& Steinberg, B. F. (2008). Motivational models for spontaneous reunification with the alienated child: Part II. American Journal of Family Therapy, 36(3), 253-261. https:// doi.org/10.1080/01926180701643230.

Demby, S. (2009). Interparent hatred and its impact on parenting: assessment in forensic custody evaluations. Psychoanalytic Inquiry, 29(6), 477-490. https://doi.org/10.1080/07351690903013959.

Fariña, F., Redondo, L., Seijo, D., Novo, M., \& Arce, R. (2017). A meta-analytic review of the MMPI validity scales and indexes to detect defensiveness in custody evaluations. International Journal of Clinical and Health Psychology, 17(2), 128-138. https:// doi.org/10.1016/j.ijchp.2017.02.002.

Fidler, B. J., \& Bala, N. (2010). Children resisting post-separation contact with a parent: concepts, controversies and conundrums. Family Court Review, 48(1), 10-47. https://doi.org/10.1111/j. 1744-1617.2009.01287.x.

Fidler, B. J., Bala, N., \& Saini, M. A. (2012). Children who resist post separation parental contact: a differential approach for legal and mental health professionals. Oxford University Press. https://doi. org/10.1093/acprof:oso/9780199895496.001.0001.

Gennari, M., \& Tamanza, G. (2017). Parental alienation (PAS) and child custody evaluation: Clinical suggestions from some cases' analysis. Maltrattamento e Abuso all'Infanzia, 1(19), 13-27. https://doi.org/10.3280/MAL2017-001002.

Goldberg, W., \& Goldberg, L. (2013). Psychotherapy with targeted parents. In A. J. L. Baker \& S. Richard Sauber (Eds.), Working with alienated children and families: a clinical guidebook (pp. 108-128). Routledge.

Gordon, R. M., Stoffey, R., \& Bottinelli, J. (2008). MMPI-2 findings of primitive defenses in alienating parents. American Journal of Family Therapy, 36(3), 211-228. https://doi.org/10.1080/ 01926180701643313.

Harman, J. J., Bernet, W., \& Harman, J. (2019). Parental alienation: the blossoming of a field of study. Current Directions in Psychological Science, 28(2), 212-217. https://doi.org/10.1177/ 0963721419827271.

Harman, J. J., Biringen, Z., Ratajack, E. M., Outland, P. L., \& Kraus, A. (2016). Parents behaving badly: gender biases in the perception of parental alienating behaviors. Journal of Family Psychology, 30(7), 866-874. https://doi.org/10.1037/fam0000232.

Harman, J. J., Kruk, E., \& Hines, D. A. (2018). Parental alienating behaviors: an unacknowledged form of family violence. Psychological Bulletin, 144(12), 1275-1299. https://doi.org/10.1037/ bul0000175. 
Harman, J. J., Leder-Elder, S., \& Biringen, Z. (2016). Prevalence of parental alienation drawn from a representative poll. Children and Youth Services Review, 66, 62-66. https://doi.org/10.1016/j. childyouth.2016.04.021.

Harman, J. J., Lorandos, D., Biringen, Z., \& Grubb, C. (2020). Gender differences in the use of parental alienating behaviors. Journal of Family Violence, 35(5), 459-469. https://doi.org/10.1007/ s10896-019-00097-5.

Johnston, J. R. (2003). Parental alignments and rejection: an empirical study of alienation in children of divorce. Journal of the American Academy of Psychiatry and the Law, 31(2), 158-170.

Johnston, J. R., \& Sullivan, M. J. (2020). Parental alienation: in search of common ground for a more differentiated theory. Family Court Review, 58(2), 270-292. https://doi.org/10.1111/fcre.12472.

Johnston, J. R., Walters, M. G., \& Olesen, N. W. (2005). Clinical ratings of parenting capacity and Rorschach protocols of custodydisputing parents: an exploratory study. Journal of Child Custody, 2(1-2), 159-178. https://doi.org/10.1300/J190v02n01_09.

Kruk, E. (2018). Parental alienation as a form of emotional child abuse: current state of knowledge and future directions for research. Family Science Review, 22(4), 141-164.

Lee-Maturana, S., Matthewson, M. L., \& Dwan, C. (2020). Targeted parents surviving parental alienation: consequences of the alienation and coping strategies. Journal of Child and Family Studies, 29, 2268-2280. https://doi.org/10.1007/s10826-020-01725-1.

Lee-Maturana, S., Matthewson, M., Dwan, C., \& Norris, K. (2019). Characteristics and experiences of targeted parents of parental alienation from their own perspective: a systematic literature review. Australian Journal of Psychology, 71(2), 83-91. https:// doi.org/10.1111/ajpy.12226.

Lorandos, D. (2020). Parental alienation in U.S. courts, 1985 to 2018. Family Court Review, 58(2), 322-339. https://doi.org/10.1111/ fcre. 12475

Lorandos, D. A., Bernet, W., \& Richard Sauber, S. (2013). Overview of parental alienation. In D. Lorandos, W. Bernet, \& S. Richard Sauber (Eds.), Parental alienation: The handbook for mental health and legal professionals. Charles $\mathrm{C}$. Thomas.

Mazza, C., Burla, F., Verrocchio, M. C., Marchetti, D., Di Domenico, A., Ferracuti, S., \& Roma, P. (2019). MMPI-2-RF profiles in child custody litigants. Frontiers in Psychiatry, 10, 75 https://doi. org/10.3389/fpsyt.2019.00725.

Mazza, C., Monaro, M., Burla, F., Colasanti, M., Orrù, G., Ferracuti, S., \& Roma, P. (2020). Use of mouse-tracking software to detect faking-good behavior on personality questionnaires: an explorative study. Scientific Reports, 10(1), 4835. https://doi.org/10. 1038/s41598-020-61636-5.

Mercer, J. (2019a). Are intensive parental alienation treatments effective and safe for children and adolescents? Journal of Child Custody, 16(1), 67-113. https://doi.org/10.1080/15379418.2018. 1557578.

Mercer, J. (2019b). Examining parental alienation treatments: problems of principles and practices. Child and Adolescent Social Work Journal, 36, 351-363. https://doi.org/10.1007/s10560-01900625-8.

Otto, R. K. (2002). Use of the MMPI-2 in forensic settings. Journal of Forensic Psychology Practice, 2(3), 71-91. https://doi.org/10. 1300/J158v02n03_05.

Pancheri, P., \& Sirigatti, S. (1995). Minnesota Multiphasic Personality Inventory-2. Organizzazioni Speciali.

Poustie, C., Matthewson, M., \& Balmer, S. (2018). The forgotten parent: the targeted parent perspective of parental alienation. Journal of Family Issues, 39(12), 3298-3323. https://doi.org/10. 1177/0192513X18777867.
Resendes, J., \& Lecci, L. (2012). Comparing the MMPI-2 scale scores of parents involved in parental competency and child custody assessments. Psychological Assessment, 24(4), 1054-1059. https://doi.org/10.1037/a0028585.

Roma, P., Marchetti, D., Mazza, C., Burla, F., \& Verrocchio, M. C. (2020a). MMPI-2 profiles of mothers engaged in parental alienation. Journal of Family Issues. https://doi.org/10.1177/ $0192513 X 20918393$.

Roma, P., Mazza, C., Mammarella, S., Mantovani, B., Mandarelli, G., \& Ferracuti, S. (2020b). Faking-good behavior in self-favorable scales of the MMPI-2? A study with time pressure. European Journal of Psychological Assessment, 36, 250-258. https://doi. org/10.1027/1015-5759/a000511.

Roma, P., Ricci, F., Kotzalidis, G. D., Abbate, L., Lavadera, A. L., Versace, G., Pazzelli, F., Togliatti, M. M., Girardi, P., \& Ferracutil, S. (2014). MMPI-2 in child custody litigation: a comparison between genders. European Journal of Psychological Assessment, 30(2), 110-116. https://doi.org/10.1027/1015-5759/a000192.

Saini, M., Johnston, J. R., Fidler, B. J., \& Bala, N. (2016). Empirical studies of alienation. In L. Drozd, M. Saini, \& N. Olesen (Eds.), Parenting plan evaluations: applied research for the family court (p. 399). Oxford University Press. https://doi.org/10.1093/med: psych/9780199754021.003.0013.

Siegel, J. C., \& Langford, J. S. (1998). MMPI-2 validity scales and suspected parental alienation syndrome. American Journal of Forensic Psychology, 16(4), 5-14.

Siegel, J. C. (1996). Traditional MMPI-2 validity indicators and initial presentation in custody evaluations. American Journal of Forensic Psychology, 14, 55-62.

Siracusano, A., Barone, Y., Lisi, G., \& Niolu, C. (2015). Parental alienation syndrome or alienating parental relational behaviour disorder: a critical overview. Journal of Psychopathology, 21, 231-238.

Tellegen, A., \& Ben-Porath, Y. S. (1992). The new uniform T-scores for the MMPI-2: rationale, derivation, and appraisal. Psychological Assessment, 4(2), 145. https://doi.org/10.1037/1040-3590.4. 2.145 .

Templer, K., Matthewson, M., Haines, J., \& Cox, G. (2017). Recommendations for best practice in response to parental alienation: findings from a systematic review. Journal of Family Therapy, 39, 103-122. https://doi.org/10.1111/1467-6427.12137.

Verrocchio, M. C., Marchetti, D., Carrozzino, D., Compare, A., \& Fulcheri, M. (2019). Depression and quality of life in adults perceiving exposure to parental alienation behaviors. Health and Quality of Life Outcomes, 17, 14 https://doi.org/10.1186/s12955019-1080-1086.

Verrocchio, M. C., Marchetti, D., Roma, P., \& Ferracuti, S. (2018). Relational and psychological features of high-conflict couples who engage in parental alienation. Ricerche di Psicologia, 41(4), 679-692. https://doi.org/10.3280/RIP2018-004008.

von Boch-Galhau, W. (2018). Parental alienation (syndrome): a serious form of child psychological abuse. Neuropsychiatrie, 32(3), 133-148. https://doi.org/10.1007/s40211-018-0267-0.

Warshak, R. A. (2010). Alienating audiences from innovation: the perils of polemics, ideology, and innuendo. Family Court Review, 48(1), 153-163. https://doi.org/10.1111/j.1744-1617.2009.01295.x.

Warshak, R. A. (2020). When evaluators get it wrong: false positive IDs and parental alienation. Psychology, Public Policy, and Law, 26(1), 54-68. https://doi.org/10.1037/law0000216.

Whitcombe, S. (2017). Powerless to parent; powerless to protect: the experiences of alienated parents in the UK. Maltrattamento $e$ abuso all'infanzia, 19(1), 47-66. https://doi.org/10.3280/ MAL2017-001004. 